\title{
Atypical chemokine receptors: from silence to sound
}

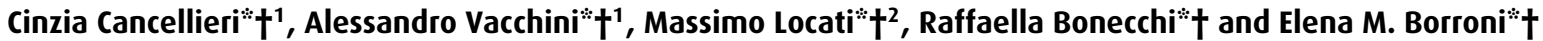 \\ "Department of Medical Biotechnologies and Translational Medicine, University of Milan, I-20089 Rozzano, Italy, and †Humanitas Clinical and Research \\ Center, I-20089 Rozzano, Italy
}

\begin{abstract}
ACRs (atypical chemokine receptors) were initially referred to as 'silent' receptors on the basis of a lack of signalling and functional activities that are typically observed with conventional chemokine receptors. Although ACRs do not directly induce cell migration, they indirectly control leucocyte recruitment by shaping chemokine gradients in tissues through degradation, transcytosis or local concentration of their cognate ligands. Recent evidence also suggests that these biological activities are supported by G-proteinindependent, $\beta$-arrestin-dependent signalling events. In the present article, we review current knowledge on structural and signalling properties of ACRs that are changing our view on this entire class of receptors from silent to endogenous $\beta$-arrestin-biased signalling receptors.
\end{abstract}

\section{Introducing the 'silent' ACRs (atypical chemokine receptors)}

Chemokines regulate leucocyte migration through the activation of a distinct family of conventional 7TMRs (seven-transmembrane domain receptors) [1]. Signalling by chemokine receptors relies on a G-protein-dependent signalling module promoting cell migration, integrated with a $\beta$-arrestin-dependent signalling module that functionally uncouples G-proteins from the receptor and subsequently desensitizes and internalizes it via clathrin-coated pitsdependent endocytosis [2,3]. In recent years it has become increasingly evident that the role of $\beta$-arrestins is not limited to receptor desensitization and internalization; their function of adaptor proteins providing diversity and finetuning of signalling activities is emerging [4]. Interestingly, it has been reported that although most 7TMRs signal in a balanced fashion through the G-protein and $\beta$-arrestin modules $[5,6]$, mutations in key residues have been shown to generate G-protein- or $\beta$-arrestin-biased receptors [4]. However, so far, $\beta$-arrestin-biased receptors have only been genetically engineered from balanced receptors by mutations in key residues involved in G-protein coupling, including the DRYLAIV motif in ICL (intracellular loop) 2 [7] and some highly conserved residues in TM (transmembrane) 2, 3 and 5 domains [8], whereas no natural cases of $\beta$-arrestin-biased receptors have been described.

Emerging evidence suggesting candidates for such $\beta$ arrestin-biased receptors are a set of chemokine receptors referred to as atypical or silent receptors, which are unable to

Key words: $\beta$-arrestin, atypical chemokine receptor, chemokine, G-protein.

Abbreviations used: ACR, atypical chemokine receptor; DARC, Duffy antigen receptor for chemokines; ICL, intracellular loop; PTX, pertussis toxin; TM, transmembrane; 7TMR, seventransmembrane domain receptor.

${ }^{1}$ These authors contributed equally to this work.

${ }^{2}$ To whom correspondence should be addressed (email massimo.locati@ humanitasresearch.it). activate the typical G-protein-mediated signalling pathways that lead to directional cell migration, presumably as a consequence of naturally occurring mutations in the domains involved in G-protein coupling [9]. This subfamily of ACR includes the DARC (Duffy antigen receptor for chemokines; also known as Duffy antigen), D6, CCRL1 (also known as CCX CKR), CCRL2 and CXCR7. Furthermore, the C5L2 receptor, which recognizes the chemotactic complement fragment C5a, also shows similar properties. Although their biology is still largely unclear, results in gene-targeted animals clearly indicate that ACRs overall act as negative regulators of inflammation and adaptive immunity [10]. Recent reports indicate that the biological functions of ACRs are G-protein-independent, but require the activation of $\beta$-arrestin-dependent signalling pathways that support their ability to generate and shape chemokine gradients in the tissue through distinct biochemical processes, including sequestration and degradation, transcytosis, or presentation of their ligand $[11,12]$. Moreover, emerging evidence suggest that the obligatory uncoupling of ACRs from G-proteins and the preferential activation of $\beta$-arrestin module may also act as a modulator of signalling activity of conventional chemokine receptors, suggesting an additional molecular mechanism for their regulatory role in leucocyte trafficking $[13,14]$. Thus the unbalanced activation of signalling modules provides the first evidence in the understanding of the molecular mechanisms underlying the loss of chemotactic activity and gain of chemokine gradient shaping functions that are peculiar to this subfamily of chemokine receptors.

\section{ACRs are not DRY}

A detailed structure-function analysis of the ACR subfamily is not available yet, but it is interesting to note that, although these receptors share high amino acids identity with conventional chemokine receptors and show high 
Figure 1 | The DRYLAIV motif in ACR

Alignment of the sequence present in the ACR of different species substituting the DRYLAIV motif observed in conventional chemokine receptors. Asterisks indicate conserved amino acids, colons indicate substitutions with similar residues.

\begin{tabular}{|c|c|c|c|c|c|c|}
\hline & CXCR7 & D6 & CCRL1 & CCRL2 & DARC & C5L2 \\
\hline Homo sapiens & RYLSIT & DKYLEIV & DRYVAVT & QRYLVFL & GHRLGAG & DLCFLAL \\
\hline Mus musculus & RYLSIT & DKYLEIV & DRYWAIT & QGYRVFS & NPRLNIG & DLFLLAF \\
\hline Rattus norvegicus & RYLSIT & DKYLEIV & DRYWAIT & QGYRVFS & -- & DLFLLAF \\
\hline Bos taurus & DRYLSVA & DKYLEIV & DRYWAVT & QRYKEFF & GPQLGAG & DLCLLAL \\
\hline Canis familiaris & RY1 & DKYLE & DRYWAVT & QRYLVFI & GPKLCAG & -- \\
\hline \multirow{2}{*}{ Sus scrofa } & DRYLSVA & DKYLEIV & DRYWAVT & QRYQKFF & --- & -- \\
\hline & $* * * * *::$ & $* * * * * * * *$ & $* * * *$ & $* *$ & $:^{*}$ & $* *: * *$ \\
\hline
\end{tabular}

affinity interactions with chemokines, they have impaired conventional signalling activities through G-proteins (i.e. intracellular calcium ion mobilization) owing to the presence of altered structural determinants supporting G-protein activation, a key signalling event in cell migration. The first identified structural element has been the DRY (Asn-ArgTyr triplet) motif located at the end of TM3, which is part of one of the most conserved motifs in the 7TMR. This amino acid triplet is highly conserved in chemokine receptors, with $100 \%$ conservation of $\mathrm{Arg}^{26}$ in TM3, and 95\% conservation of both an aromatic residue in position 27 of TM3 and a negatively charged residue in position 25 of TM3. This motif plays a pivotal role in receptor activation, being involved in the exchange of GDP with GTP and thus activating the G-protein for further downstream signalling [15,16], as also exemplified in CCR5 where mutation of $\mathrm{Arg}^{26}$ in TM3 to the neutral asparagine disrupted chemokine-induced Gprotein coupling despite retaining binding affinity for the ligand [17]. ACRs either lack the DRY motif (i.e. DARC) or exhibit a modified DRY motif and/or DRYLAIV consensus (Figure 1). Interestingly, the presence of altered DRYLAIV consensus in ACR is unlikely to simply represent a lossof-function mutation, as similar alterations in this motif are observed for the same ACRs across species, suggesting some selective pressure to maintain a specific altered DRYLAIV motif within a specific ACR (Figure 1). These observations raise the intriguing question of whether corrections of mutated DRYLAIV consensus are enough to restore missed G-protein signalling activities of ACRs, and vice versa, whether modifications in this consensus are enough to switch a conventional chemokine receptor into an ACR. Interestingly, replacement of the CXCR7 ICL2 with the corresponding CXCR4 domain does not result in a G-protein signalling-competent CXCR7 chimaera [18], and signalling competency was only partially achieved when this motif was retromutated to the conventional DRYLAIV consensus in D6 [19] or C5L2 [20]. Similarly, although replacement of arginine by asparagine in the CCR 5 DRY motif impairs its G-protein coupling efficiency and chemotaxis activity [17], chemical inhibition of the $G_{\alpha i}$ signalling module through PTX (pertussis toxin) treatment did not confer ACR features on the receptor (E.M. Borroni, unpublished work), indicating that besides G-protein uncoupling by the modified DRY motif, additional structural features are required to convert a conventional chemokine receptor into an ACR.

\section{DRY and beyond: structural degeneration of micro-switch elements in ACRs}

Surprisingly, modifications of DRYLAIV consensus are also present in the conventional chemokine receptors XCR1 and CXCR6, both known to signal via PTX-sensitive $G_{\alpha i}$ proteins $[21,22]$. This confirms that a mutated DRY motif does not represent a reliable indicator for the lack of Gprotein coupling, and that, at least in the case of some 7TMRs, the DRYLAIV consensus is not the only determinant of G-protein coupling and that additional sequences are likely to be involved. Crystallographic analysis of 7TMRs has recently revealed that the majority of the conserved residues involved in G-protein activation are part of the so-called micro-switch elements that include the DRY motif in TM3, the CWXP motif in TM6, and the NPXXY ${ }^{5-6} \mathrm{~F}$ motif in TM7 [23] (Figure 2). Recently, multiple amino acid sequence alignment and in silico modelling of the tertiary structures of ACRs and conventional chemokine receptors have revealed that these sites are also the most likely structural elements accounting for the functional differentiation between the two receptor subfamilies [24] (Figure 2). These observations clearly suggest that, besides the DRY motif, the degenerations of other motifs and functional residues involved in G-protein activation may be related to functional changes typical of ACRs. For example, the conventional DRY motif is present in CCRL1 and CXCR7 but the CWXP and NPXXY ${ }^{5-6} \mathrm{~F}$ motifs of these receptors show significant differences, suggesting that constraints for amino acid conservation at these motif sites active for conventional chemokine receptors are lost in these ACRs, possibly explaining their impaired ability to activate G-protein signalling [24] (Figure 2). Interestingly, in addition to micro-switch elements, other highly conserved sites in the TM regions of conventional chemokine receptors are not conserved in several ACRs, suggesting that the use of different amino acid residues at such sites may lead to relevant functional and/or structural changes [24] (Figure 2). As several of these residues are located in TM3 or ICL2, which are important for the selectivity of receptor-G-protein interactions and the efficiency of G-protein activation [25], the modifications detected on the loops may be involved in the loss of the conventional signalling functions of ACR. A detailed examination of these predictions is needed in order to better understand the mechanism of G-protein-independent signalling of ACRs.

\section{Are ACRs G-protein-null receptors?}

On the basis of their impairment in intracellular calcium mobilization and chemotaxis activities, ACRs have always been referred to as 'silent' chemokine receptors. A detailed analysis of data in literature, however, raises the question of whether ACRs are really completely unable to activate 
Figure 2 Micro-switch elements in ACR

(A) DRYLAIV motif in TM3. (B) CWXP motif in TM6. (C) NPXXY5-6 F motif in TM7. The sequence of CXCR4 is shown as a representative example of a conventional chemokine receptor, and the consensus sequences observed across all conventional chemokine receptors are enclosed by grey boxes. The position of the first and the last residue of aligned sequence are indicated. Amino acid residues statistically divergent from the consensus sequence, as reported by Daiyasu et al. [24], are underlined and bold. C5L2 was not included in the statistical analysis. (D) 7TMR showing the alignment of micro-switch elements in human ACR.

A

\begin{tabular}{|c|c|c|}
\hline eceptor & & DRYLAIV \\
\hline CXCR4 & 127 & LAFISLDRYLAIVHATNSQRPRK-LLAEKVV- 156 \\
\hline CXCR7 & 135 & LTCMSVDRYLSITYETNTPSSRK-KMVRRVV- 164 \\
\hline D6 & 135 & ISCMSLDKYLEIVHĀㅁYY \\
\hline CCRL1 & 130 & 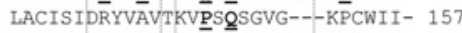 \\
\hline CCRL2 & 121 & NCLLTVQRYLVFLHKG \\
\hline ARC & 148 & GCHASLG̈HRLGAGQV̄PGLTLG---------L- 169 \\
\hline \multirow[t]{2}{*}{ C5L2 } & 125 & LAALSADLCFLALGPAWWSTVQR-ACGVQVAC 155 \\
\hline & & raz \\
\hline
\end{tabular}

B Receptor

CXCR4
CXCR7
D6
CCRL1
CCRL2
DARC
CSL2

C

\begin{tabular}{|c|c|c|c|}
\hline Receptor & & $N P_{x x y}$ & \\
\hline CXCR4 & 293 & FHCCLNPILYAFLG-AKFKTSAQ & 314 \\
\hline CXCR7 & 306 & VHCCVNPVLYSFIN-RNYRYELM & 327 \\
\hline D6 & 303 & LHCCFSPILYAFS $\overline{\mathbf{S}}-$ HRFRQYLK & 324 \\
\hline CCRL1 & 294 & FHSCLNPILYVFMG-ASFKNYVM & 315 \\
\hline CCRL2 & 291 & THCCINPLLYAFLD-GTFSKYLC & 312 \\
\hline DARC & 295 & LHCVATPLLLALFCHQATRTLLP & 317 \\
\hline \multirow[t]{2}{*}{ C5L2 } & 282 & AHSCLNPMLFLYFG-RA---QLR & 300 \\
\hline & & Cterminal domain & \\
\hline
\end{tabular}

\section{$C W \times P$} $\begin{array}{lll}214 & \text { VILSCYCIIISKLSHSKGHQKRKALKTTVILILAFFACWLPYYIG } & 258 \\ 227 & \text { IIAVEYFLIARAISASSDQEKHSSRKIIFSYVVVFLCWLPYHVA } & 271 \\ 225 & \text { AMIFFYSRIGGVLVRLRPAGQGRALIAAALVVAFFVLFPYNLT } & 269 \\ 215 & \text { IMGVCYFITARTLMKMPNIKISRPLKVLLTVVIVFIVTQLPYNIV } & 259 \\ 215 & \text { IFTFLYVQMRTLRFR--EQRYSLFKLVFAIMVVFLIMWAPYNIA } & 257 \\ 222 & \text { PLGLFGAKGL------KALGMGPGPWMILWAWFIFWWPHGVV } & 259 \\ 215 & \text { AVASCHSALL--CWAARRCRP-----LGTAIVVGFFVCWAPYHLL } & 252\end{array}$ TME

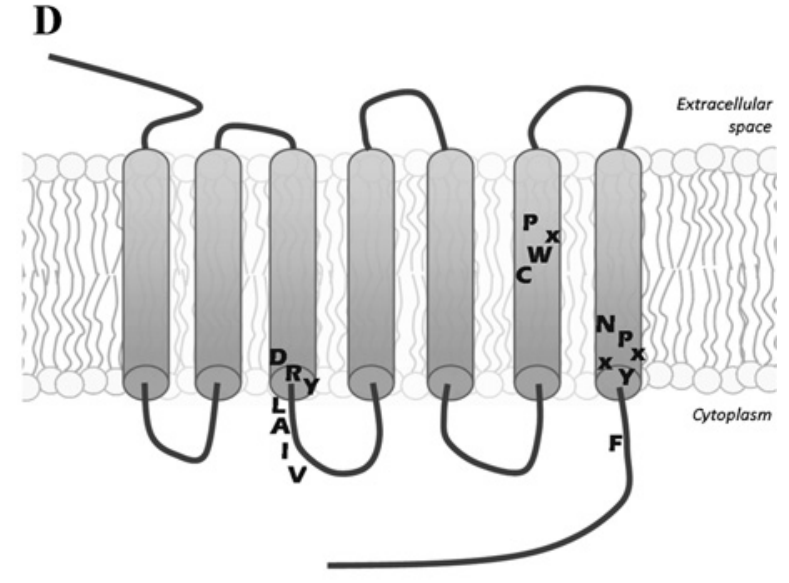

G-protein signalling. For example, Cain and Monk [26] demonstrated that C5L2 couples weakly with $G_{\alpha \mathrm{i}}$ protein as a low level of PTX-sensitive signal transduction can occur following ligand binding, and we have recently observed that following ligand engagement, D6 is not coupled with $G_{\alpha s}$ and $G_{\alpha q}$ but retains a residual $G_{\alpha \mathrm{i}}$ activation, although this is not required for its scavenger activity (E.M. Borroni, unpublished work). However, the most intriguing observations refer to CXCR7. Although several studies failed to demonstrate CXCR7-dependent activation of G-protein on either CXCL12 or CXCL11 engagement [18,27], recently it was shown to retain the ability to control proliferation and migration of primary astrocytes through a CXCL12-dependent $\mathrm{G}_{\alpha \mathrm{i}}$-mediated signalling pathway $[28,29]$, whereas its signalling activity induced by CXCL11 was completely unaffected by PTX treatment. It is also noteworthy that, besides modifications in structural motifs required for G-protein activation, the preferential intracellular localization may represent a second aspect of ACR biology contributing to their reduced ability to activate G-protein-dependent signalling. In fact, the lower expression of ACRs on the cell surface compared with the conventional chemokine receptors results in a reduced number of receptor copies available for ligand binding and this may reflect the weak activation of G-protein signalling, possibly insufficient to support cell migration. Thus, although their G-protein signalling activity is not completely abrogated, structural and trafficking properties appear to cause ACRs to be not best suited to signal through the classical G-protein-dependent pathway, raising the intriguing hypothesis that some ACRs may also act as conditional conventional chemokine receptors under specific circumstances influencing their trafficking properties. Moreover, it is tempting to speculate that the residual G-protein activation may sustain some presently unknown subordinate biological activities of ACRs, unrelated to their classical functions associated with the shaping of chemokine gradients.

\section{ACRs and $\beta$-arrestins: a fatal attraction}

Conventional chemokine receptors use ligand-driven signals to couple receptors to the endocytic machinery through the association with $\beta$-arrestins, a response that reduces surface receptor levels and desensitizes the remaining surface receptors to further stimulation [30]. It has recently been demonstrated that replacement of arginine by asparagine in the CCR5 DRY motif abrogates its G-protein activation properties and reduces receptor stability at the plasma membrane as a consequence of its constitutive internalization 
Figure 3 | Alignment of ACR C-terminal domains

Alignment of the C-terminal domain of ACR of different species. The position of the last residue of aligned sequences is indicated. Serine/threonine clusters are white coloured and highlighted in grey. Asterisks indicate conserved amino acids, colons indicate substitutions with similar residues.

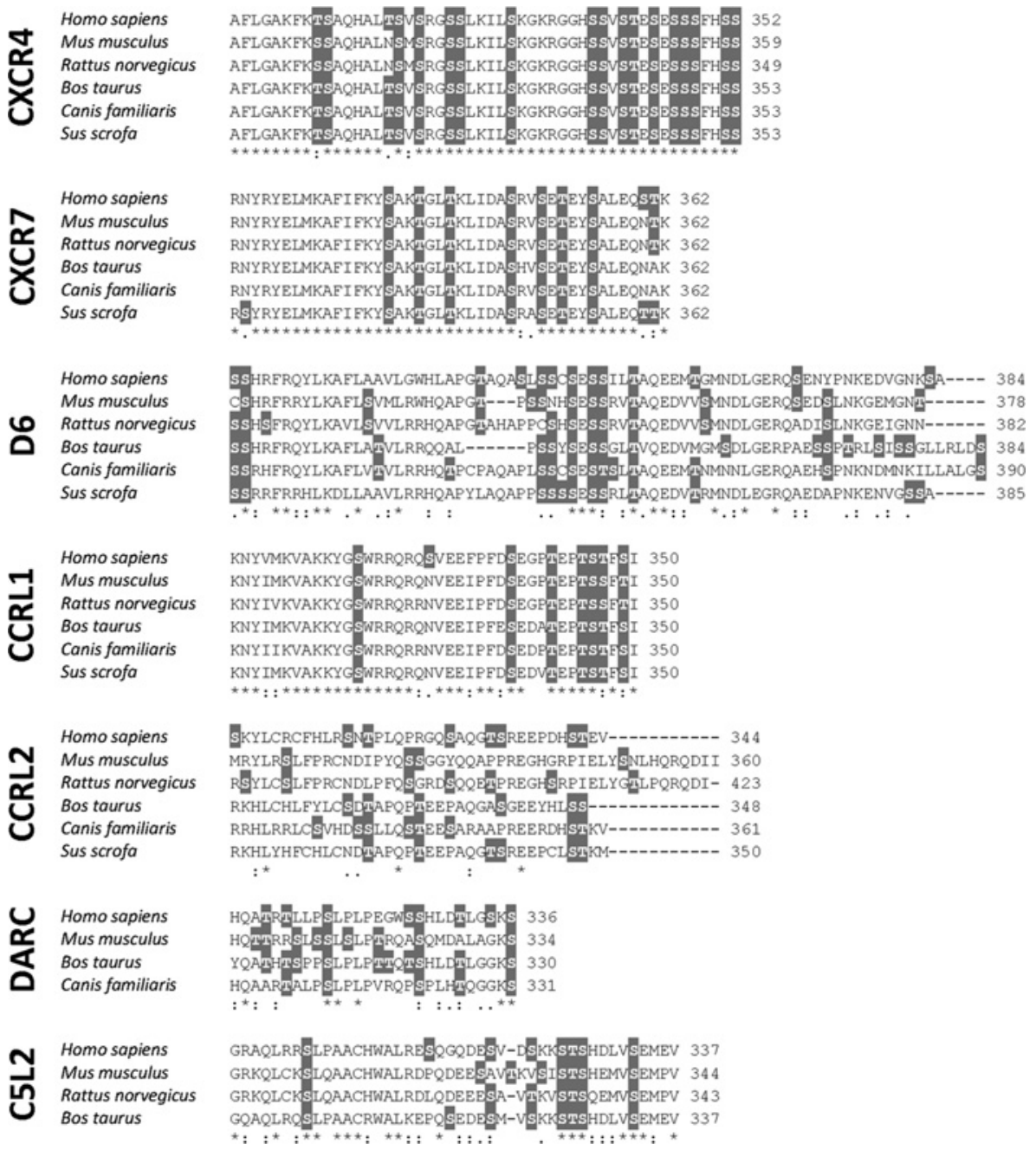

due to constitutive phosphorylation and interaction with $\beta$ arrestins [17]. Interestingly, the same features have been observed in ACRs, suggesting that association with $\beta$-arrestins plays a major role in receptor internalization and recycling. For example, agonist activation of C5L2 results in relocalization to endocytic vesicles and association to the receptor of $\beta$-arrestin-2 [12]. CXCR7 also interacts with $\beta$-arrestin2 in basal conditions, and ligand engagement significantly enhances this interaction [31], and D6 relocalizes $\beta$-arrestins within the cytoplasm even in the absence of ligand $[32,33]$.

It is well established that $\beta$-arrestins can directly interact with chemokine receptors via at least two distinct sites located in ICLs and the C-terminal domain respectively [34]. The C-terminal domain of some ACRs is particularly rich in serine/threonine residues involved in direct physical interaction with $\beta$-arrestins $[33,35,36]$. Although the need for their phosphorylation is still unclear [32,33], these serine/threonine clusters are well conserved across different species, further supporting their potential role in ACR biology (Figure 3). In this respect, several studies have identified the interaction of ACR intracellular tail with $\beta$ arrestins as a critical event for receptor stability, trafficking and chemokine uptake from the extracellular space and degradation $[18,33,35,37]$. For example, $\beta$-arrestins regulate CXCR7 level in early endosomes, promoting proper receptor endosomal sorting, whereas internalized ligand undergoes lysosomal degradation [38]. Likewise, $\beta$-arrestin- 1 promotes D6 adaptive up-regulation from endosomal compartment to plasma membrane, increasing efficiency in chemokine uptake and degradation (E.M. Borroni, unpublished work).

\section{Are ACRs $\beta$-arrestins-biased signalling receptors?}

For a long time, 7TMRs, including chemokine receptors, have been thought to signal exclusively through G-proteins and 
be desensitized by $\beta$-arrestins [39]. It is now appreciated that $\beta$-arrestins act as multifunctional adapter proteins also involved in signalling, and 7TMRs are currently thought to signal through G-protein- and $\beta$-arrestin-mediated pathways in a balanced fashion [4]. Specific mutations can bias signalling towards $\beta$-arrestin or G-protein signaling [8], as in the case of CCR5 where replacement of arginine by asparagine in the DRY motif was shown to abrogate G-protein signalling and to result in receptor constitutive phosphorylation and association with $\beta$-arrestins [17]. The observation that ACRs present similar modification in the DRY motif and associate with $\beta$-arrestins, raised the hypothesis that these receptors may operate as $\beta$-arrestin-biased receptors. Indeed, although the literature indicates that ACRs do not require G-protein signalling to exert their biological activities, evidence suggest non-conventional signalling activities for these receptors. Several studies clearly demonstrated a negative modulation of signalling properties of conventional chemokine receptors by some ACRs, including C5L2 [40], CXCR7 [27], DARC [41] and D6 [14], and recent findings have identified the intracellular signalling molecule in $\beta$-arrestin that is involved in this cross-talk $[13,41,42]$. Further evidence suggests that ACRs could support $\beta$-arrestin-dependent signalling has been provided by the observation that the effects of CXCR7 on cancer cell adhesion and survival and on tumour angiogenesis $[43,44]$ require activation of Akt and Erk1/2 through a $\beta$-arrestin-mediated process $[11,45]$. Finally, we have reported that D6 trafficking properties are affected by D6 ligands that are driven to degradation after receptor engagement, whereas other chemokines, including protease-inactivated chemokines, bind with similar affinity to the receptor but have no influence on its cellular distribution and are not degraded [46,47], clearly indicating a ligand-dependent modulation of D6 biological properties. We have recently collected evidence suggesting that D6 adaptive up-regulation and chemokine scavenging activity results from its ability to activate a $\beta$-arrestin-1dependent Rac1-PAK1-LIMK1 signalling pathway leading to cofilin phosphorylation and cytoskeletal reorganization (E.M. Borroni, unpublished work). Taken together, these observations demonstrate that ACRs are active receptors capable of signalling through $\beta$-arrestins and thus represent the first described subfamily of $\beta$-arrestin-biased 7TMR.

\section{Concluding remarks}

The unbalanced activation of signalling modules provides a first conceptual element in the understanding of the molecular mechanisms underlying the loss of chemotactic activity and gain of chemokine gradient-shaping functions specific to the ACR. The current results suggest that ACRs are 'silent' rather than 'sound' receptors, laying the groundwork to review the definition of this subfamily of chemokine receptors as endogenous $\beta$-arrestin-biased signalling receptors, which evolution has naturally engineered from balanced chemokine receptors via mutations of key residues involved in G-protein coupling. Finally, these new insights into ACR signalling properties may lead to the identification of innovative therapeutic approaches aimed at regulating chemokines to control immune responses.

\section{Funding}

This study was supported by the European Community's Seventh Framework Programme (FP7-2007-2013) [grant number HEALTHF4-2011-281608 (TIMER)], Ministero dell'Istruzione dell'Università e della Ricerca [Progetti di Ricerca di Interesse Nazionale (PRIN) projects 2002061255 and 2007-ENYMAN-003; and Fondo per gli Investimenti della Ricerca di Base (FIRB) project RBFR08CW8G], Fondo Humanitas per la Ricerca and Italian Association for Cancer Research (AIRC)

\section{References}

1 Charo, I.F. and Ransohoff, R.M. (2006) The many roles of chemokines and chemokine receptors in inflammation. N. Engl. J. Med. 354, 610-621

2 Thelen, M. and Stein, J.V. (2008) How chemokines invite leukocytes to dance. Nat. Immunol. 9, 953-959

3 Neel, N.F., Schutyser, E., Sai, J., Fan, G.H. and Richmond, A (2005) Chemokine receptor internalization and intracellular trafficking. Cytokine Growth Factor Rev. 16, 637-658

4 Shenoy, S.K. and Lefkowitz, R.J. (2011) $\beta$-Arrestin-mediated receptor trafficking and signal transduction. Trends Pharmacol. Sci. $\mathbf{3 2}$ 521-533

5 Schwartz, T.W., Frimurer, T.M., Holst, B., Rosenkilde, M.M. and Elling, C.E. (2006) Molecular mechanism of 7TM receptor activation: a global toggle switch model. Annu. Rev. Pharmacol. Toxicol. 46, 481-519

6 Rajagopal, K., Lefkowitz, R.J. and Rockman, H.A. (2005) When 7 transmembrane receptors are not G protein-coupled receptors. J. Clin. Invest. 115, 2971-2974

7 Wei, H., Ahn, S., Shenoy, S.K., Karnik, S.S., Hunyady, L., Luttrell, L.M. and Lefkowitz, R.J. (2003) Independent $\beta$-arrestin 2 and $\mathrm{G}$ protein-mediated pathways for angiotensin II activation of extracellular signal-regulated kinases 1 and 2. Proc. Natl. Acad. Sci. U.S.A. 100, 10782-10787

8 Shenoy, S.K., Drake, M.T., Nelson, C.D., Houtz, D.A., Xiao, K., Madabushi, S., Reiter, E., Premont, R.T., Lichtarge, 0. and Lefkowitz, R.J. (2006) $\beta$-Arrestin-dependent, G protein-independent ERK1/2 activation by the $\beta_{2}$ adrenergic receptor. J. Biol. Chem. 281, 1261-1273

9 Bonecchi, R., Savino, B., Borroni, E.M., Mantovani, A. and Locati, M. (2010) Chemokine decoy receptors: structure-function and biological properties. Curr. Top. Microbiol. Immunol. 341, 15-36

10 Bonecchi, R., Galliera, E., Borroni, E.M., Corsi, M.M., Locati, M. and Mantovani, A. (2009) Chemokines and chemokine receptors: an overview. Front. Biosci. 14, 540-551

11 Rajagopal, S., Kim, J., Ahn, S., Craig, S., Lam, C.M., Gerard, N.P., Gerard, C. and Lefkowitz, R.). (2010) $\beta$-Arrestin but not G protein-mediated signaling by the 'decoy' receptor CXCR7. Proc. Natl. Acad. Sci. U.S.A. 107, 628-632

12 Van Lith, L.H., Oosterom, J., Van Elsas, A. and Zaman, G.J. (2009) C5a-stimulated recruitment of $\beta$-arrestin2 to the nonsignaling 7-transmembrane decoy receptor C5L2. J. Biomol. Screening 14 1067-1075

13 Bamberg, C.E., Mackay, C.R., Lee, H., Zahra, D., Jackson, J., Lim, Y.S. Whitfeld, P.L., Craig, S., Corsini, E., Lu, B. et al. (2010) The C5a receptor (C5aR) C5L2 is a modulator of C5aR-mediated signal transduction. J. Biol. Chem. 285, 7633-7644

14 Bonecchi, R., Locati, M., Galliera, E., Vulcano, M., Sironi, M., Fra, A.M., Gobbi, M., Vecchi, A., Sozzani, S., Haribabu, B. et al. (2004) Differential recognition and scavenging of native and truncated macrophage-derived chemokine (macrophage-derived chemokine/CC chemokine ligand 22) by the D6 decoy receptor. J. Immunol. 172, 4972-4976

15 Mirzadegan, T., Benko, G., Filipek, S. and Palczewski, K. (2003) Sequence analyses of $\mathrm{G}$-protein-coupled receptors: similarities to rhodopsin. Biochemistry 42, 2759-2767

16 Oldham, W.M. and Hamm, H.E. (2008) Heterotrimeric G protein activation by G-protein-coupled receptors. Nat. Rev. Mol. Cell Biol. 9 , 60-71 
17 Lagane, B., Ballet, S., Planchenault, T., Balabanian, K., Le Poul, E., Blanpain, C., Percherancier, Y., Staropoli, I., Vassart, G., Oppermann, M et al. (2005) Mutation of the DRY motif reveals different structural requirements for the CC chemokine receptor 5-mediated signaling and receptor endocytosis. Mol. Pharmacol. 67, 1966-1976

18 Hoffmann, F., Müller, W., Schütz, D., Penfold, M.E., Wong, Y.H., Schulz, S. and Stumm, R. (2012) Rapid uptake and degradation of CXCL12 depend on CXCR7 carboxyl-terminal serine/threonine residues. J. Biol. Chem 287, 28362-28377

19 Nibbs, R., Graham, G. and Rot, A. (2003) Chemokines on the move: control by the chemokine 'interceptors' Duffy blood group antigen and D6. Semin. Immunol. 15, 287-294

20 Okinaga, S., Slattery, D., Humbles, A., Zsengeller, Z., Morteau, O., Kinrade, M.B., Brodbeck, R.M., Krause, J.E., Choe, H.R., Gerard, N.P. and Gerard, C. (2003) C5L2, a nonsignaling C5A binding protein. Biochemistry 42 9406-9415

21 Yoshida, T., Imai, T., Kakizaki, M., Nishimura, M., Takagi, S. and Yoshie, 0. (1998) Identification of single C motif-1/lymphotactin receptor XCR1. J. Biol. Chem. 273, 16551-16554

22 Chandrasekar, B., Bysani, S. and Mummidi, S. (2004) CXCL16 signals via $\mathrm{Gi}$, phosphatidylinositol 3-kinase, Akt, I $\kappa \mathrm{B}$ kinase, and nuclear factor- $\kappa \mathrm{B}$ and induces cell-cell adhesion and aortic smooth muscle cell proliferation. J. Biol. Chem. 279, 3188-3196

23 Nygaard, R., Frimurer, T.M., Holst, B., Rosenkilde, M.M. and Schwartz, T.W. (2009) Ligand binding and micro-switches in 7TM receptor structures. Trends Pharmacol. Sci. 30, 249-259

24 Daiyasu, H., Nemoto, W. and Toh, H. (2012) Evolutionary analysis of functional divergence among chemokine receptors, decoy receptors, and viral receptors. Front. Microbiol. 3, 264

25 Gether, U. (2000) Uncovering molecular mechanisms involved in activation of G protein-coupled receptors. Endocr. Rev. 21, 90-113

26 Cain, S.A. and Monk, P.N. (2002) The orphan receptor C5L2 has high affinity binding sites for complement fragments C5a and C5a des-Arg ${ }^{74}$. J. Biol. Chem. 277, 7165-7169

27 Levoye, A., Balabanian, K., Baleux, F., Bachelerie, F. and Lagane, B (2009) CXCR7 heterodimerizes with CXCR4 and regulates CXCL12-mediated G protein signaling. Blood 113, 6085-6093

28 Odemis, V., Lipfert, J., Kraft, R., Hajek, P. Abraham, G., Hattermann, K. Mentlein, R. and Engele, J. (2012) The presumed atypical chemokine receptor $C X C R 7$ signals through $\mathrm{G}(\mathrm{i} / 0)$ proteins in primary rodent astrocytes and human glioma cells. Glia $\mathbf{6 0}, 372-381$

29 Lipfert, J., Odemis, V. and Engele, J. (2013) Grk2 is an essential regulator of CXCR7 signalling in astrocytes. Cell. Mol. Neurobiol. 33, 111-118

30 Shenoy, S.K. and Lefkowitz, R.J. (2003) Multifaceted roles of $\beta$-arrestins in the regulation of seven-membrane-spanning receptor trafficking and signalling. Biochem. J. 375, 503-515

31 Luker, K.E., Gupta, M., Steele, I.M., Foerster, B.R. and Luker, G.D. (2009) Imaging ligand-dependent activation of CXCR7. Neoplasia $\mathbf{1 1}$ 1022-1035

32 Galliera, E., Jala, V.R., Trent, J.O., Bonecchi, R., Signorelli, P., Lefkowitz, R.J., Mantovani, A., Locati, M. and Haribabu, B. (2004) $\beta$-Arrestin-dependent constitutive internalization of the human chemokine decoy receptor D6. J. Biol. Chem. 279, 25590-25597

33 McCulloch, C.V., Morrow, V., Milasta, S., Comerford, I., Milligan, G., Graham, G.J., Isaacs, N.W. and Nibbs, R.J. (2008) Multiple roles for the c-terminal tail of the chemokine scavenger D6. J. Biol. Chem. 283 7972-7982
34 Huttenrauch, F., Nitzki, A., Lin, F.T., Honing, S. and Oppermann, M (2002) $\beta$-Arrestin binding to CC chemokine receptor 5 requires multiple c-terminal receptor phosphorylation sites and involves a conserved Asp-Arg-Tyr sequence motif. J. Biol. Chem. 277, 30769-30777

35 Ray, P., Mihalko, L.A., Coggins, N.L., Moudgil, P., Ehrlich, A., Luker, K.E. and Luker, G.D. (2012) Carboxy-terminus of CXCR7 regulates receptor localization and function. Int. J. Biochem. Cell Biol. 44, 669-678

36 Cui, W., Simaan, M., Laporte, S., Lodge, R. and Cianflone, K (2009) C5aand ASP-mediated C5L2 activation, endocytosis and recycling are lost in S323I-C5L2 mutation. Mol. Immunol. 46, 3086-3098

37 Canals, M., Scholten, D.J., de Munnik, S., Han, M.K., Smit, M.J. and Leurs, R. (2012) Ubiquitination of CXCR7 controls receptor trafficking. PLOS ONE 7, e34192

38 Mahabaleshwar, H., Tarbashevich, K., Nowak, M., Brand, M. and Raz, E. (2012) $\beta$-Arrestin control of late endosomal sorting facilitates decoy receptor function and chemokine gradient formation. Development 139 2897-2902

39 Ferguson, S.S. (2001) Evolving concepts in G protein-coupled receptor endocytosis: the role in receptor desensitization and signaling. Pharmacol. Rev. 53, 1-24

40 Rittirsch, D., Flierl, M.A., Nadeau, B.A., Day, D.E., Huber-Lang, M., Mackay, C.R., Zetoune, F.S., Gerard, N.P., Cianflone, K., Köhl, J. et al. (2008) Functional roles for C5a receptors in sepsis. Nat. Med. 14, 551-557

41 Chakera, A., Seeber, R.M., John, A.E., Eidne, K.A. and Greaves, D.R. (2008) The duffy antigen/receptor for chemokines exists in an oligomeric form in living cells and functionally antagonizes CCR5 signaling through hetero-oligomerization. Mol. Pharmacol. 73, 1362-1370

42 Zabel, B.A., Wang, Y., Lewén, S., Berahovich, R.D., Penfold, M.E., Zhang, P., Powers, J., Summers, B.C., Miao, Z., Zhao, B. et al. (2009) Elucidation of CXCR7-mediated signaling events and inhibition of CXCR4-mediated tumor cell transendothelial migration by CXCR7 ligands. J. Immunol. 183 3204-3211

43 Burns, J.M., Summers, B.C., Wang, Y., Melikian, A., Berahovich, R., Miao Z., Penfold, M.E., Sunshine, M.J., Littman, D.R., Kuo, C.J. et al. (2006) A novel chemokine receptor for SDF-1 and I-TAC involved in cell survival, cell adhesion, and tumor development. J. Exp. Med. 203, 2201-2213

44 Wang, J., Shiozawa, Y., Wang, J., Wang, Y., Jung, Y., Pienta, K.J., Mehra, R., Loberg, R. and Taichman, R.S. (2008) The role of CXCR7/RDC1 as a chemokine receptor for CXCL12/SDF-1 in prostate cancer. J. Biol. Chem. 283, 4283-4294

45 Heinrich, E.L., Lee, W., Lu, J., Lowy, A.M. and Kim, J. (2012) Chemokine CXCL12 activates dual CXCR4 and CXCR7-mediated signaling pathways in pancreatic cancer cells. J. Transl. Med. 10,68

46 Bonecchi, R., Borroni, E.M., Anselmo, A., Doni, A., Savino, B., Mirolo, M. Fabbri, M., Jala, V.R., Haribabu, B., Mantovani, A. and Locati, M. (2008) Regulation of D6 chemokine scavenging activity by ligand- and Rab11-dependent surface up-regulation. Blood 112, 493-503

47 Savino, B., Borroni, E.M., Torres, N.M., Proost, P., Struyf, S., Mortier, A., Mantovani, A., Locati, M. and Bonecchi, R. (2009) Recognition versus adaptive up-regulation and degradation of CC chemokines by the chemokine decoy receptor D6 are determined by their N-terminal sequence. J. Biol. Chem. 284, 26207-26215

Received 21 September 2012

doi:10.1042/BST20120246 